Pak. j. sci. ind. res. Ser. B: biol. sci. 201356 (1) 1-10

\title{
Entomophily, Ornithophily and Anemochory in the Highly Self-incompatible Boswellia ovalifoliolata Bal. \& Henry (Burseraceae), an Endemic and Endangered Medicinal Tree Species
}

\author{
Aluri Jacob Solomon Raju*, Pakkurti Vara Lakshmi and Kunuku Venkata Ramana \\ Department of Environmental Sciences, Andhra University, Visakhapatnam 530 003, India \\ (received September 14, 2010; revised January 16, 2012; accepted February 25, 2012)
}

\begin{abstract}
Boswellia ovalifoliolata (Burseraceae) has been investigated for its reproductive biology. Its flowering, fruiting and seed dispersal events occur in leafless state during dry season. The flowers are small, bisexual, mildly odoriferous and actinomorphic; weakly protandrous but strictly self-incompatible. Insects and sunbirds pollinate the flowers but floral characteristics suggest that entomophily is the principal mode. Bud and flower feeding by a weevil and flower and fruit feeding by the Palm Squirrel have been found to be greatly affecting the success of sexual reproduction. The garden lizard serves as a predator of pollinating insects, especially bees and wasps; while acting so it affects the pollination rate in this tree species. Fruit set in open-pollination is below $10 \%$ while it is up to $34 \%$ in manual cross-pollination. The study suggests that limitation of cross-pollination, space constraint for seed production from all ovules of the flower and availability of limited resources to the tree with rocky, dry and limited litter in the floor of the forest seem to be the constraints for higher fruit set. Mature fruits dehisce and disseminate their light weight, papery and winged seeds with the aid of wind. The study site being windy provides the necessary driving force for effective dispersal of seeds away from parental trees. Seed germination occurs following rainfall but the growth and development of seedlings depends on soil water and nutritional status. Field observations indicate that the success rate of seedling recruitment is highly limited and it could be due to nutrient-poor soil and water stress resulting from dry spells during rainy season.
\end{abstract}

Keywords: Boswellia ovalifoliolata, self-incompatibility, entomophily, ornithophily, anemochory

\section{Introduction}

The genus Boswellia belongs to the Burseraceae family and is widely distributed in the dry regions of tropical Africa, Arabia and India. In Africa, it is distributed in Somalia, Ethiopia, Eritrea, Kenya, Sudan, Tanzania, Madagascar and some other countries. In Arabia, it is mainly restricted to Yemen, Oman and Socotra. In India, it is distributed in a few regions such as Rajasthan, south east Punjab, Danwara and Madras. There are about 18 species of Boswellia which are shrubs or trees with outer bark often flaking. They include $B$. sacra, B. frereana, B. neglecta, B. microphylla, B. papyrifera, $B$. ogadensis, B. pirottae, B. rivae, B. madagascariensis, $B$. socotrana, B. popoviana, $B$. nana, $B$. ameero, $B$. bullata, $B$. dioscoridis, B. elongata, $B$. serrata and $B$. ovalifoliolata. Only the last two species have been reported to be distributed in India (Latheef et al., 2008; Arabia, 2005). Sunnichan et al. (2005) mentioned that $B$. serrata is the only species found in India. But, other workers reported that $B$. ovalifoliolata occurs on the

*Author for correspondence; E-mail: ajsraju@yahoo.com foothills of the Seshachalam hill ranges of Eastern Ghats in Chittoor, Cuddapah and Kurnool districts of Andhra Pradesh up to an altitude of about $600-900 \mathrm{~m}$. It is a globally endangered, strict endemic medium-sized deciduous medicinally important tree species and listed in CITES Red Data Book under medicinal plants list (Sandhya and Pullaiah, 2002; Sudhakara et al., 2002). Chetty et al. (2002) reported that both B. serrata and $B$. ovalifoliolata occur at the foothills of Seshachalam hill ranges of Eastern Ghats.

Reproductive biology information is available for only a few species of Burseraceae such as Commiphora weightii, Bursera medranoana, Sentiria laevigata and Boswellia serrata (Sunnichan et al., 2005). B ovalifoliolata has not been investigated for its reproductive biology despite its medicinal importance in India. Our field surveys in the areas of Tirumala Hills, Andhra Pradesh, India, have shown that the local tribes and others make deep incisions on the main trunk to extract the gum and resin causing damage to trees which in turn leading to the depletion of the plant population in 
the natural habitat. The gum together with other undisclosed combinations is used extensively to cure a number of diseases: mouth, throat and stomach ulcers, fever, stomach pain, ulcers, scorpion sting, amoebic dysentery, hydrocele, etc. The decoction of the bark is used for joint or rheumatic pains (Latheef et al., 2008; Henry, 2006). With this backdrop, B. ovalifoliolata has been investigated for its reproductive biology in its natural 3 area and the observations and results obtained are discussed in the light of the existing relevant information. The findings presented in this paper are important to understand the relationship between $B$. ovalifoliolata and insects and birds of the region during dry season. Further, the report also forms the basis for taking effective conservation and management measures for the studied plant species as well as the dependent insects and birds.

\section{Materials and Methods}

The study area included Kapilatheertham and Deer Park areas of Tirumala Hills (lat. $13^{\circ} 42^{\prime} \mathrm{N}$, long. $79^{\circ} 20^{\prime} \mathrm{E}$ and alt. 2,463 ft.) of the Southern Eastern Ghats in Andhra Pradesh. The approximate number of trees of B. ovalifoliolata was 150 at Kapilatheertham and 60 at Deer Park. The trees occur mostly as small clusters at the former area while they are mostly scattered at the latter area. In both areas, the associated tree species are almost same and they include Zizyphus rugosa (Rhamnaceae), Erythroxylum monogynum (Erythroxylaceae), Spondias pinnata, Buchanania axillaris (Anacardiaceae), Gyrocarpus asiaticus (Hernandiaceae), Dalbergia paniculata (Fabaceae), Schleichera oleosa (Sapindaceae), Ochna obtusata (Ochnaceae), Hugonia mystax (Linaceae), Ficus mollis (Moraceae) and Azadirachta indica (Meliaceae). Of these, only the last one blooms during the flowering season of $B$. ovalifoliolata. The floor of the area was completely dry with exposed rocks during summer but it covered with luxuriant growth of herbaceous flora and grasses during rainy season. Field studies were carried out on the reproductive ecology of $B$. ovali-foliolata during 20072010. The overall timing of leaf fall, leaf flushing, flowering and fruiting events was recorded. The number of flowers per inflorescence $(\mathrm{N}=20)$ was recorded for ten selected inflorescences, two each from five trees. These inflorescences were simultaneously followed for their flowering duration. The floral characteristics were recorded from twenty five flowers collected from five each from five trees. Mature flower buds on ten inflorescences were tagged and followed for recording the time of flower opening. The same flowers were followed for recording the time of anther dehiscence. The pollen grain characteristics were recorded by consulting the book of Bhattacharya et al. (2006). Pollen production per flower was calculated following the method described by Cruden (1977). Pollen fertility was assessed by staining them in $1 \%$ acetocarmine. Stigma receptivity, nectar volume, sugar concentration and sugar types, and amino acids were assessed by following the methods prescribed by Dafni et al. (2005). Fifty mature buds, five each from ten inflorescences on five trees were bagged a day before anthesis without manual self pollination to know whether fruit set occurs through autogamy. Another set of fifty mature buds was selected in the same way, then emasculated and bagged a day prior to anthesis. The next day, the bags were removed and the stigmas were brushed with the freshly dehisced anthers from the flowers of the same tree and re-bagged to know whether fruit set occurs through geitonogamy. Ten trees were selected for manual crosspollination and open-pollination. One hundred and twenty five flowers were used per each tree for manual cross-pollination. For this, mature buds were emasculated and bagged a day prior to anthesis. The next day, the bags were removed; freshly dehisced anthers from flowers of another tree were brushed on the stigma and re-bagged. Ten inflorescences on each tree were tagged and followed for fruit set in open-pollination (Sunnichan et al. 2005). The length of time followed for each of these breeding systems was 6 weeks. Twenty stigmas, four each from five trees were removed at $1500 \mathrm{~h}$ and observed them under microscope for the number of pollen grains deposited by pollen vectors. The per cent of flower predation by an unidentified weevil was calculated by counting the number of damaged flowers on 50 selected inflorescences on ten trees. Preliminary investigations on foraging activity of foragers were made at different times of the day including dawn and dusk periods. Based on this information, the number of foraging visits made by each forager species was counted for $15 \mathrm{~min}$ in each hour during the entire period of the day. This data was used to calculate the total number of foraging visits made by each species for the entire day and also to calculate the total number of foraging visits made by each category of foragers in order to evaluate their relative importance and role in effecting pollination. The forage collected and the area of contact of the species with the floral sex organs were also observed to understand their role in pollination. Binoculars were specially used for this purpose. Field 
observations on fruit, seed and seedling ecology were also made to the extent possible due to certain restrictions in the study areas.

\section{Results and Discussion}

In B. ovalifoliolata (Fig. 1a), leaf shedding occurs during December-February, and flowering from $1^{\text {st }}$ week of March to $2^{\text {nd }}$ week of April at population level. An individual tree flowers for about 3 weeks only. Leaf flushing occurs from $3^{\text {rd }}$ week of April and continues through rainy season. In a few trees, flowering occurs before the fall of old leaves but complete leaf shedding occurs when flowering is at its peak. The leaves are imparipinnate and crowded at the ends of branches. The flowers are borne in branched panicles at the ends of branches (Fig.1b). Each branch produces 8 to 10 inflorescences and each inflorescence produces $35.2 \pm$ 13.77 (Range 16-72) flowers over a period of 5-14 days. The flowers are pedicellate, greenish white, $6 \mathrm{~mm}$ long, $5 \mathrm{~mm}$ across, mildly fragrant, cup-shaped, bisexual and actinomorphic. The sepals are five, minute, basally connate, imbricate, light green, lightly pubescent outside and persistent without any further growth during postfertilization stage in fruited flowers. The petals are five, white, free, imbricate, $5 \mathrm{~mm}$ long and erect. Stamens are inserted outside a fleshy annular pinkish-red nectary disc which is present outside the ovary at the flower base. They are ten arranged in two whorls, each with $2 \mathrm{~mm}$ long white filament and $1 \mathrm{~mm}$ long dorsifixed yellow dithecous anther (Fig. 1c). The pistil is clearly distinguished into ovary, style and stigma. The ovary is superior, trilocular, each locule with two pendulous ovules borne on axile placentation. The style is light pink at base and dark green above, $4 \mathrm{~mm}$ long and trilobed. The stigma is short, capitate, shiny and wet papillate type (Fig.1e,f).

The flowers open during 1100-1300 h. A fully open flower shows petals in erect position exposing the stamens and stigma. The stigma extends $1 \mathrm{~mm}$ beyond the anthers and remains in that state throughout the flower life. Anther dehiscence is nearly synchronous with flower opening. The anthers dehisce by longitudinal slits along the theca and release pollen grains. The pollen grains are light yellow, sticky, tricolporate with smooth exine and $66.4 \mu \mathrm{m}$ in size (Fig. 1d). An anther produces $683.4 \pm 40.97$ (Range 602-748) pollen grains while the total pollen output per flower is 6834 of which $72 \%$ is fertile and the remaining per cent sterile. The fertile pollen to ovule ratio is $820.1: 1$. The stigma attains receptivity $2 \mathrm{~h}$ after anthesis and remains receptive until the noon of the next day. A flower produces $0.4 \pm 0.15$ $\mu \mathrm{L}$ of nectar with $53.8 \pm 1.75 \%$ (Range $51-56 \%$ ) sugar concentration. The nectar sugars include glucose, fructose and sucrose; the last one is more dominant. The nectar also contains both essential and non-essential amino acids. The essential amino acids are arginine, histidine, lysine and threonine while the non-essential amino acids are alanine, aspartic acid, cysteine, glysine, hydroxyproline, serine, glutamic acid and tyrosine. The flowers drop off by the evening of the $2^{\text {nd }}$ day if not pollinated while only pistil and sepals remain intact in pollinated flowers.

The flowers offer both pollen and nectar. They were foraged by insects and sunbirds during daytime throughout the flowering season. The insect foragers included bees, wasps, flies and butterflies. The bees included Apis dorsata (Fig. 1g), A. cerana, A. florea, Trigona iridipennis (Fig.1h), Ceratina sp. (Fig.1i), Xylocopa latipes (Fig.1j) and X. pubescens (Fig.1k). Juvenile Xylocopa bees were nectar foragers while all other bees were nectar and pollen foragers (Table 1). Apis and Trigona bees foraged throughout the day from 0700-1800 $\mathrm{h}$ while the other bees during 0800-1300 $\mathrm{h}$ (Fig.2). The wasps included Scolia sp., Rhynchium sp. (Fig.1o), Eumenes sp. (Fig.1n), Eumenes petiolata (Fig. $1 \mathrm{~m})$ and E. conica (Fig. 11). They were exclusively nectar foragers and their foraging visits were almost confined to $0800-1400 \mathrm{~h}$ (Fig.3). The flies represented Hyperalonia sp. only (Fig.1p); it collected only nectar during 0800-1200 h (Fig.4). Butterflies included 4 species - Catopsilia pomona (Fig.1q), Junonia lemonias (Fig.5a), Acraea violae (Fig.5b,c) and Danaus chrysippus (Fig.5d). They were nectar foragers and visited the flowers during 0800-1700 $\mathrm{h}$ (Fig.6). The sunbirds were Nectarinia asiatica (Fig.5f,g) and N. zeylonica; they visited the flowers day long from 0700 to $1800 \mathrm{~h}$ with more foraging activity during 1000-1300 h (Fig. 7). Of the total insect and sunbird visits, bee visits constituted $62 \%$, wasps $17 \%$, sunbirds $12 \%$, butterflies $7 \%$ and flies 2\% (Fig.8). Other passerine birds such as Pycnonotus jocosus, P. cafer, Pericrocotus cinnamomeus, Dicrurus adsimilis, D. caerulescens, Parus xanthogenys, Turdoides striatus, Motacilla flava, and a non-passerine bird, Megalaima haemacephala also visited the flowering trees in quest of nectar but discontinued flower-probing immediately (Table 1).

All insect categories after landing probed the flowers for nectar and/or pollen. The forehead and ventral 
surface of the body of the insects except butterflies were found to be contacting the anthers and stigma invariably while probing the flower for nectar.

The bees while collecting pollen from the anthers normally contacted the stigma on their underside and hence were considered to be transferring pollen and effecting pollination. Trigona bees tended to stay mostly on the same tree for forage collection effecting mostly self-pollinations. Apis, Ceratina and juvenile Xylocopa bees made frequent inter-tree flights in search of more
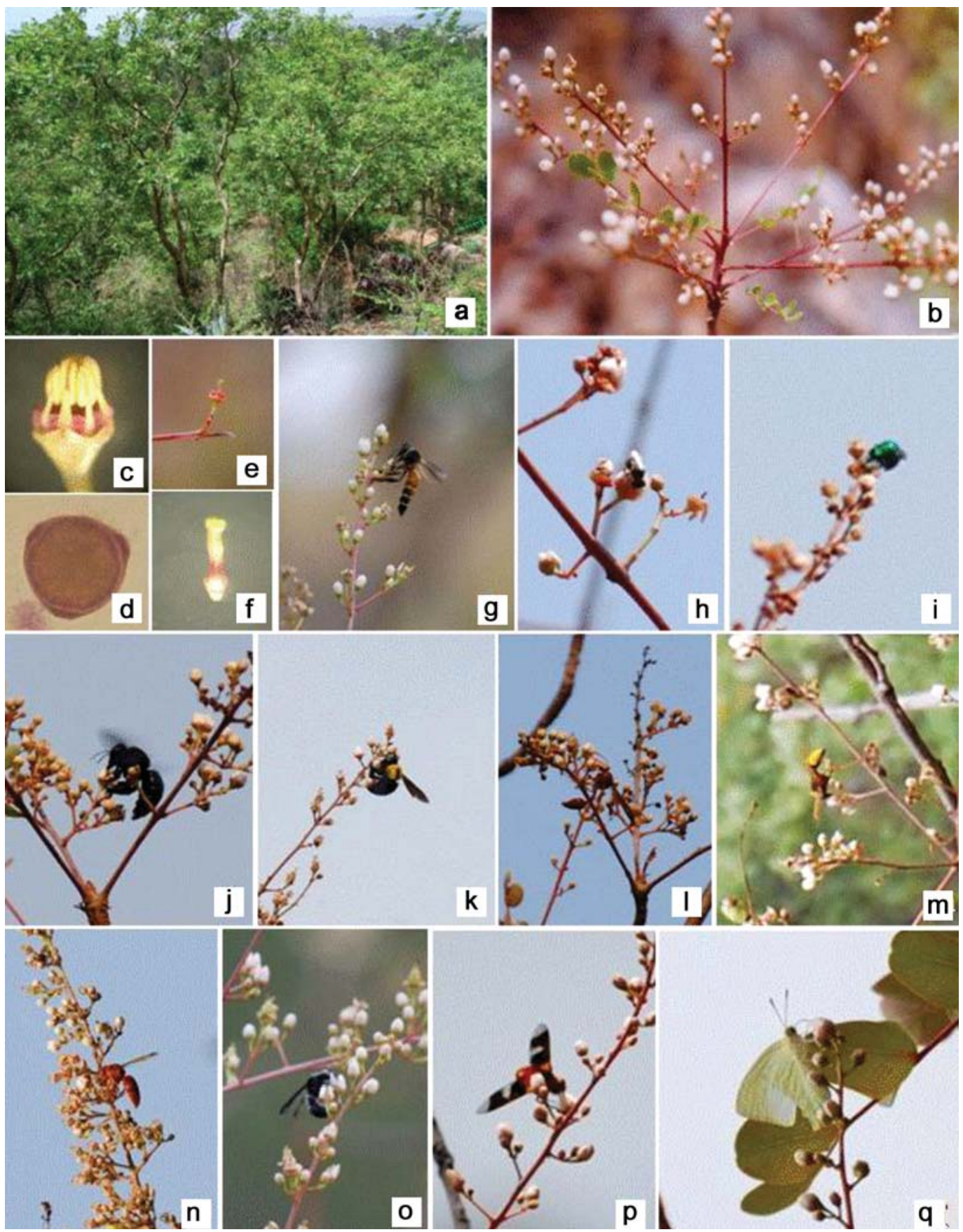

Fig. 1. Boswellia ovalifoliolata; a, Tree; b, Flowering in florenscence; c, Position of stamens; d, Pollen grain; e and f, Pistil; g, Apis dorsata; h, Trigona indipennis; i, Ceration sp; j, Xybopa lalipes; k, Xybaxpa pubescens; 1, Eumenes petiolata; m, Eumenes petiolata; n, Eumenes sp., o, Rhynchium sp; p, Hyperalonia sp; q, Catopsilia pomona. 
Table 1. Fruit set under open pollination and manual xenogamous cross-pollinations on 10 selected trees of Tirumala Hill population

\begin{tabular}{lll}
\hline \hline $\begin{array}{l}\text { Tree } \\
\text { number }\end{array}$ & $\begin{array}{l}\text { Fruit set }(\%) \\
\text { (open pollination) }\end{array}$ & $\begin{array}{l}\text { Fruit set }(\%) \\
\text { (hand cross-pollination)** }\end{array}$ \\
\hline TH1 & 4.3 & 24.2 \\
TH2 & 9.8 & 12.0 \\
TH3 & 3.4 & 19.2 \\
TH4 & 2.4 & 19.0 \\
TH5 & 2.9 & 31.6 \\
TH6 & 4.1 & 26.4 \\
TH7 & 4.0 & 15.2 \\
TH8 & 1.8 & 16.8 \\
TH9 & 8.7 & 33.7 \\
TH10 & 4.1 & 10.8 \\
\hline \hline
\end{tabular}

$*=$ average of 10 inflorescences/tree; ** = average of 125 pollinations/tree.

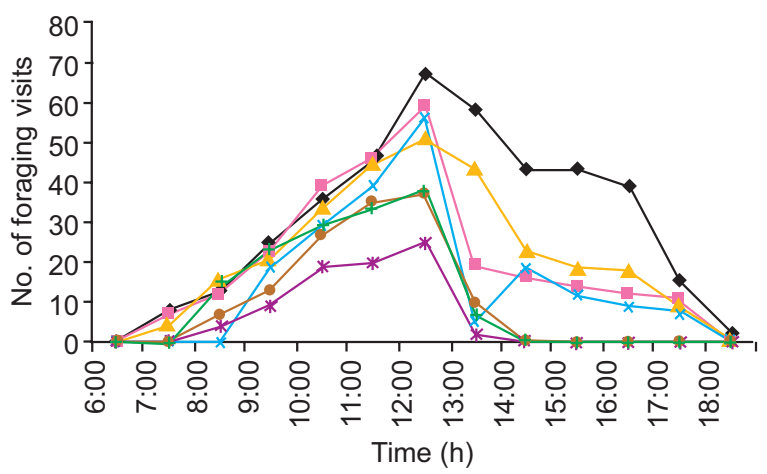

$\rightarrow$ Apis dorata $\rightarrow$ Apis cerana $\_$Apis florea $*$ Trigona iridipennis

* Ceratina sp. $\rightarrow$ Xylocopa latipes + Xylocopa pubescens

Fig. 2. Hourly foraging activity of bees on B. ovalifoliolata.

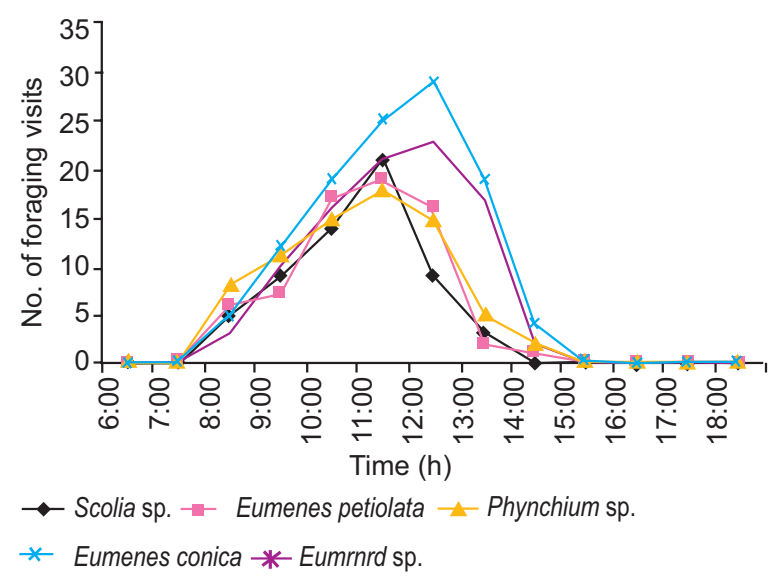

Fig. 3. Hourly foraging activity of wasps on B. ovalifoliolata.

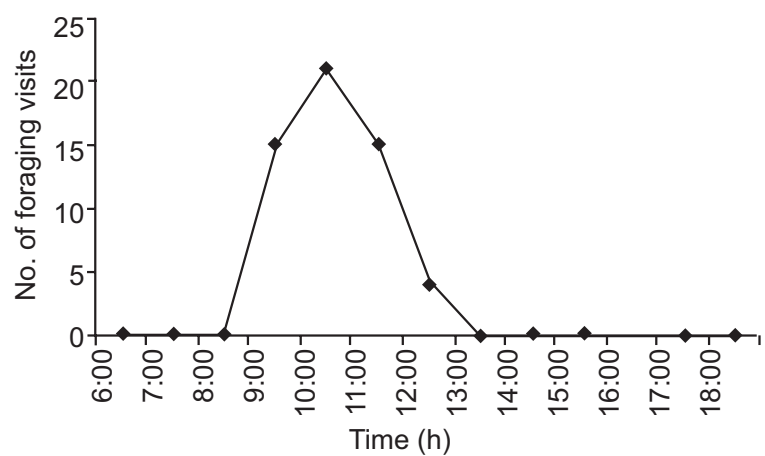

Fig. 4. Hourly foraging activity of the Dipteran, Hyperalonia sp. on B. ovalifoliolata.

forage. Wasps also exhibited similar foraging behaviour. The fly tended to forage mostly on the same tree collecting nectar very slowly from each visited flower. The butterflies made frequent inter-tree flights in quest of more nectar; they inserted proboscis through the stamens as well as from the sides of the petals for nectar collection. The oriental garden lizard, Calotes versicolor (Order: Squamata, Family: Agamidae) was found to lie in wait closely to the flowers to capture the foraging insects (Fig. 5e). The prey species for this lizard were mainly the foraging bees and wasps. Sunbirds landed on the inflorescence branches, walked to the flowers and inserting their curved beak to collect nectar; while doing so, the beak invariably contacted both the stigma and stamens and such a contact was considered to be transferring pollen and effecting pollination.

The inflorescences with mature buds when bagged without emasculation did not set any fruit. Further, the manual flower-to-flower selfing carried out on certain inflorescences of the same tree also did not produce any fruit. In different trees, the fruit set varied from 10.8 to $33.7 \%$ in manual cross-pollinations while it ranged from 1.8 to $9.8 \%$ in open pollinations (Table 2). A weevil species was found feeding on buds and flowers (Fig. 5j,k); the percent of bud predation is $18 \%$ and that of flower predation is $27 \%$. Further, the rodent, threestriped palm squirrel, Funambulus palmarum (Family: Sciuridae) was found to be feeding on flowers and fruits (Fig. 5h,i). The exact percentage of flowers and fruits fed could not be estimated due to difficulty in accessing the flowering branches and in following the feeding activity of the squirrel in the forest. But, visual observations indicated that the squirrel fed voraciously on flowers and growing fruits showing a significant effect on the reproductive success of the plant.

Natural fruit set rate is $9.3 \pm 4.63$ (Range 2-24) at inflorescence level (Fig. 51). The average flower to fruit 


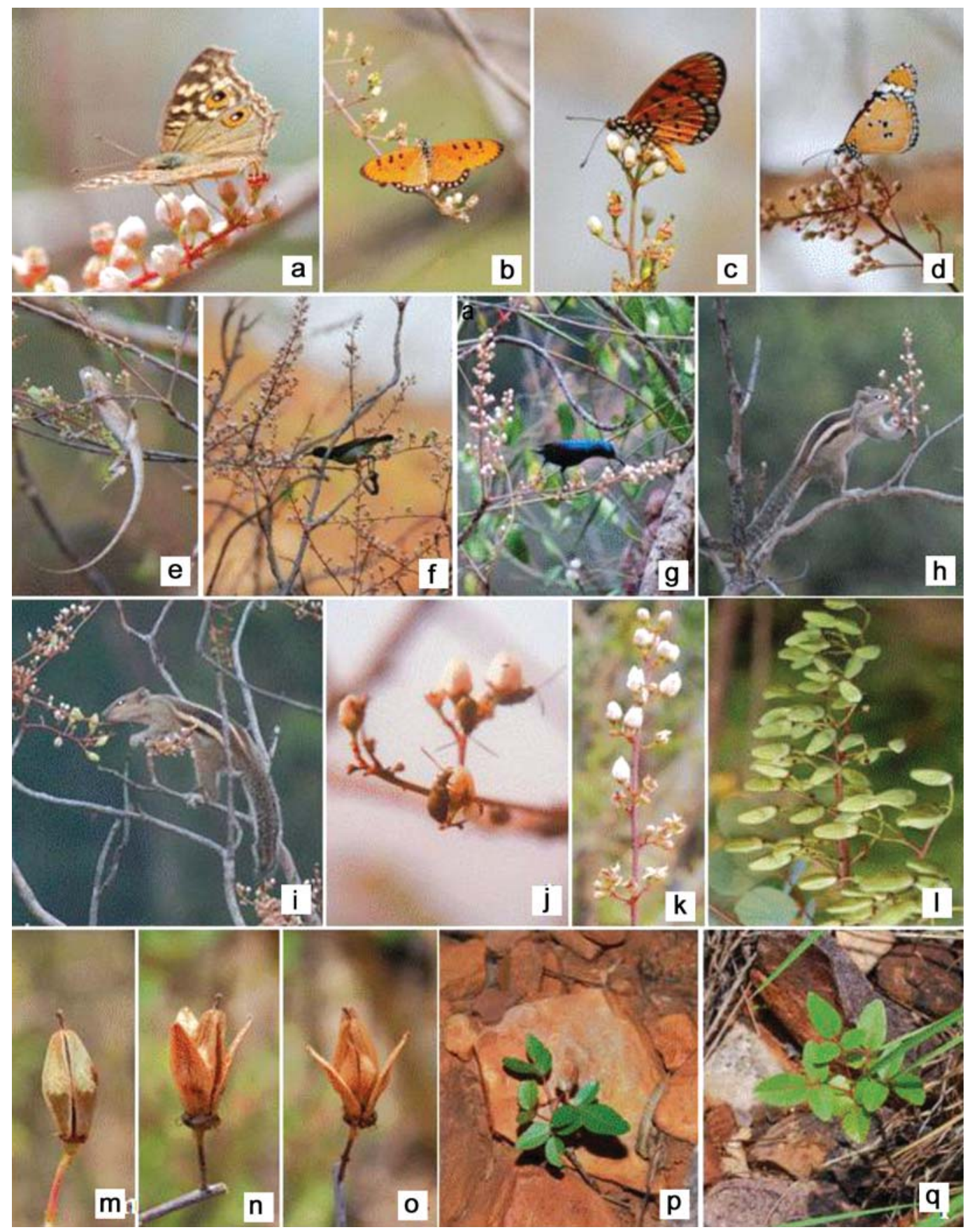

Fig. 5. Boswellia ovalifoliolata a, Junonia lemonias; b and c Acraea violae; d, Danaus chrysippus; e, f and g, Nectarinia asiatica (male and female); h and i Funambulus palmarum (flower and fruit feeding); $\mathrm{j}$ and $\mathrm{k}$, Weevil feeding on buds and flowers; 1 , Fruit set; $\mathrm{m}$, Maturing fruit; $\mathrm{n}$ and o Fruit dehiscence; $\mathrm{p}$ and $\mathrm{q}$ Healthy seedlings.

ratio is 3.7: 1 . The fruit is initially light green (Fig. $5 \mathrm{~m}$ ), then creamy white and light brown when mature. It grows to a maximum length of 13-14 $\mathrm{mm}$ and of $6 \mathrm{~mm}$ width in 4 weeks. It is a simple septicidal trigonous capsule with a weight of $179 \pm 26.6 \mathrm{mg}$ and invariably produces three seeds against the actual six ovules in a flower. The ovule to seed ratio is $2: 1$. The seeds are winged, papery, compressed, $7 \mathrm{~mm}$ long, $4 \mathrm{~mm}$ wide and $19.9 \pm 3.1 \mathrm{mg}$ weight. The fruits dehisce along the septa to disseminate seeds into the air by the end of May (Fig. 5n,o). The seeds being light in weight disseminate easily by the wind. Study site is windy and 
Table 2. Fruit set under open pollination and manual xenogamous cross-pollinations on 10 selected trees of Tirumala Hill population

\begin{tabular}{lll}
\hline \hline $\begin{array}{l}\text { Tree } \\
\text { number }\end{array}$ & $\begin{array}{l}\text { Fruit set (\%) } \\
\text { (open pollination)* }\end{array}$ & $\begin{array}{l}\text { Fruit set }(\%) \\
\text { (hand cross-pollination)** }\end{array}$ \\
\hline KT1 & 4.3 & 24.2 \\
KT2 & 9.8 & 12.0 \\
KT3 & 3.4 & 19.2 \\
KT4 & 2.4 & 19.0 \\
KT5 & 2.9 & 31.6 \\
DP1 & 4.1 & 26.4 \\
DP2 & 4.0 & 15.2 \\
DP3 & 1.8 & 16.8 \\
DP4 & 8.7 & 33.7 \\
DP5 & 4.1 & 10.8 \\
\hline \hline
\end{tabular}

* = average of 10 inflorescences/tree; ** = average of 125 pollinations/tree; KT = kapilatheertham; DP: deer park.

the seeds are disseminated to distances up to $400 \mathrm{~m}$ in the downhill side. The seeds germinate following monsoon showers in June-July (Fig. 5p,q) but the success rate seemed to be dependant on the continuity of rain and the nutritional status of soil. Some seedlings were found to show symptoms of chlorosis which may be due to water and nutrient deficient soils in rocky habitats.

B. ovalifoliolata is a deciduous tree species because it is leafless during flowering phase. Leaf flushing occurs almost at the end of fruiting. In a few trees, leaf flushing is a little bit early when fruits are still green and young. The short flowering period evidenced at individual as well as population level, massive blooming and the position of panicle inflorescences at the end of branches serve as a cue for foragers to collect floral rewards from the flowers.

The floral characteristics of $B$. ovalifoliolata such as fresh mild odour, hidden nectar in modest quantity and pinkish red nectary disc serving as nectar guide conform to bee-flowers (Faegri and van der Pijl, 1979). But, the small flower size, delicate petals and actinomorphic symmetry are not suitable for foraging visits by Xylocopa bees (Faegri and van der Pijl, 1979). However, the flowers withstand the small-sized juvenile bees of Xylocopa due to their light weight. The observed $X y$ locopa bees are juveniles because they emerge from brood during March-April (Raju and Rao, 2006) and hence they are suitable for probing the flowers to collect nectar. These juvenile bees in quest of nectar for instant energy and for overcoming dehydration make multiple visits to closely and distantly spaced flowering trees of
B. ovalifoliolata. Such consistent flower visits between trees effect and enhance cross-pollination rate. Apis, Trigona and Ceratina bees collect pollen and nectar with ease due to cup-like flower shape with exposed floral rewards. Baker and Baker $(1983 ; 1982)$ stated that short-tongued bees such as the bees observed in this study tend to be rewarded with sucrose-rich nectar. Further, Cruden et al. (1983) reported that in dry seasonal forest plants, the nectar concentration is usually high and bee-flowers produce a small volume of nectar with high sugar concentration. In B. ovalifoliolata, the flowers produce a small volume of sucrose-rich nectar with high sugar concentration and hence conform to the generalizations stated by Baker and Baker $(1983 ; 1982)$ and Cruden et al. (1983). In line with this, bees recorded consistently visit the flowers of different trees to collect forage and in doing so effect pollination. Apis dorsata being a large-bodied bee requires more energy and hence efficiently probes the flowers in quick succession on the same and different trees until it is saturated with the forage; its foraging visits to different conspecific trees not only effect but also enhance cross-pollination rate. Other Apis species, Ceratina and Trigona bees with slow mobility between conspecific trees for forage collection mostly effect self-pollination which is not the mode of breeding system in B. ovalifoliolata. Hence, these bees have a minor role in cross-pollination. Wasps usually take nectar as a supplement food, especially when brood nursing is over. They are active in blossoms towards the end of flowering season in seasonal climates. Wasp-flowers are also sucrose-rich but are usually unreliable and unsteady pollinators (Faegri and van der Pij1, 1979). The floral nectar of B. ovalifoliolata being

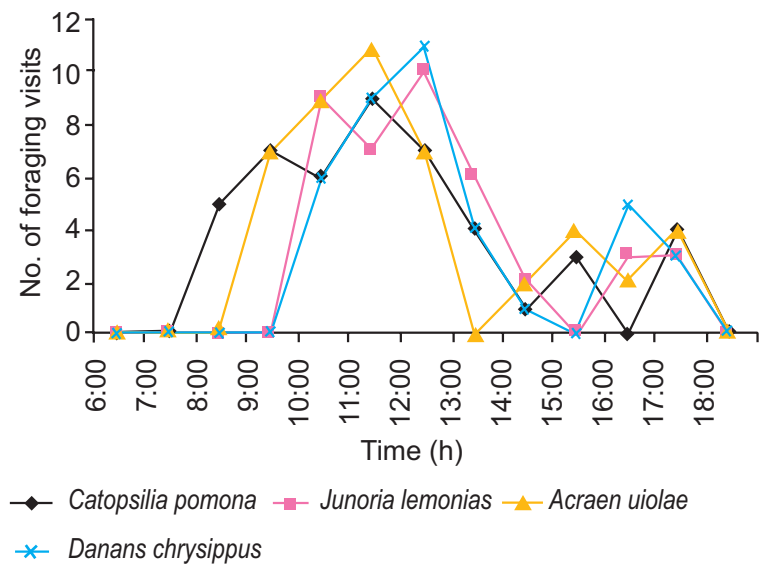

Fig. 6. Hourly foraging activity of the butterflies on B. ovalifoliolata. 


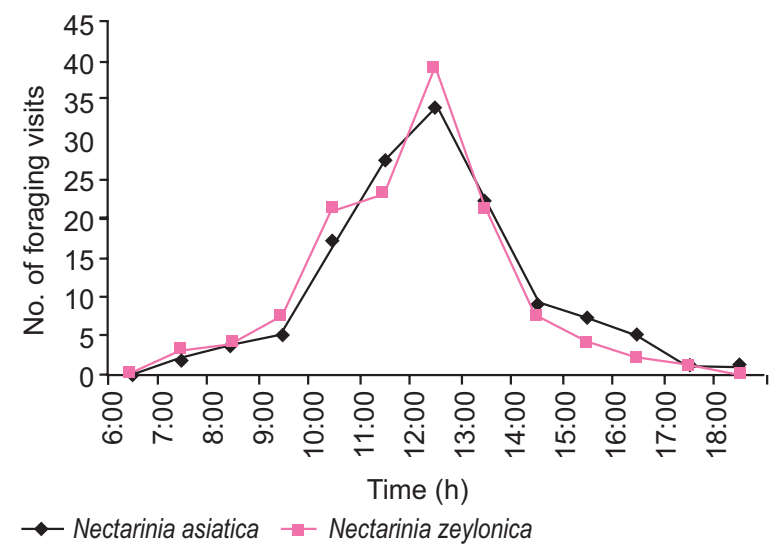

Fig. 7. Hourly foraging activity of sunbirds on B. ovalifoliolata.

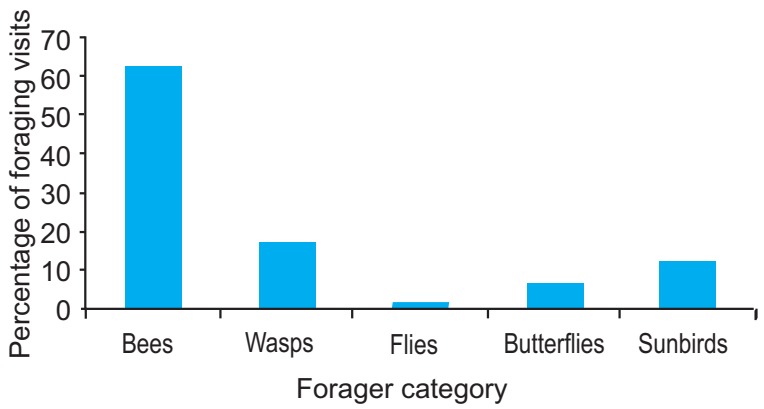

Fig. 8. Relative percentage of foraging visits of different categories of insects and sunbirds on B. ovalifoliolata.

sucrose-rich is favoured by the wasps, Scolia, Eumenes and Rhynchium. Their visits to the flowers throughout the flowering season suggests that their brood nursing period is over and hence, they are active in flowers to take nectar as a supplement diet. However, they are not consistent foragers like bees but they use this floral source until exhausted and their frequent inter-tree movement during their foraging period contributes to cross-pollination. The garden lizard is an ambush predator capturing the foraging insects at the flowers of $B$. ovalifoliolata. The foraging insects cannot perceive the lizard and do not respond by predator-avoidance behaviour. The lizard does not attack the prey until it forages on a flower for a considerable period. It is for this reason that the pollinator insects have greater opportunity of being approached and attacked by the lizard. The predation of the lizard on pollinating insects has its share in reducing the cross-pollination rate in $B$. ovalifoliolata. The role of dipteran fly in cross-pollination appears to be negligible due to its restricted inter-tree mobility. Butterfly-flowers also produce a small volume of sucrose-rich nectar with high sugar concentration
(Opler, 1983; Cruden et al., 1983; Baker and Baker, $1983 ; 1982)$. As the floral nectar of B. ovalifoliolata is characterized in this way, the foraging visits of the observed species of butterflies on this tree are not surprising. As they make frequent flights between trees, their foraging visits also contribute to cross-pollination. All these insect species carry considerable number of pollen grains on their body/proboscis, the character of which qualifies them as effective and efficient pollinators. The foraging activity of these insects coincides well with the timing of anthesis; it gradually increases from anthesis onwards, reaches to peak around noon and gradually decreases towards the evening. In B. serrata, honey bees have been reported to be the exclusive pollinators (Sunnichan et al., 2005).

Ornithophilous flowers are large, tend to be red, deep seated with concealed nectar. They secrete high volume of hexose-rich nectar with low sugar concentration (Baker and Baker, 1990; Cruden et al., 1983; Opler, 1983). On the contrary, in the present study, the sunbirds visit $B$. ovalifoliolata flowers which are small, cupshaped and white with a small volume of sucrose-rich nectar with high sugar concentration. Since the nectar volume is very small and sunbirds require a greater amount of energy per flower, they visit different conspecific trees in quest of more nectar. Such a foraging behaviour results in cross-pollination. These sunbirds exhibit fidelity to this floral source until exhausted. Several other birds also attempt to collect nectar from $B$. ovalifoliolata but soon discontinue probing the flowers. The study shows that $B$. ovalifoliolata is not ornithophilous but sunbirds use it as nectar source for survival during dry season while other birds are unable to use it even in the absence of dry season blooming ornithophilous tree species in the study area. Therefore, the birds recorded in the study area appear to be searching for the floral nectar to meet their food/energy requirement during dry season.

Insects require ten essential amino acids but all of them are not normally found in all nectars. Usually, three to four essential amino acids and several non-essential amino acids are found in floral nectars (Baker and Baker, 1983; 1982). Baker and Baker (1986) reported that the amino acids add taste to the floral nectar and it depends on their concentration. Their presence serves as an important cue for insects to make flower visits and in the process effect pollination. In B. ovalifoliolata, the nectar contains some essential and non-essential amino acids. Its nectar is an important source for four 
of the ten essential amino acids required by insects for their growth and development (DeGroot, 1953). They include arginine, histidine, lysine and threonine. Nonessential amino acids are metabolized by insects from the food they take; however, floral nectar provides some of these amino acids instantaneously. The nectar of $B$. ovalifoliolata provides alanine, aspartic acid, cysteine, glysine, hydroxyproline, serine, glutamic acid and tyrosine. Therefore, the insects and also sunbirds by visiting and pollinating the flowers derive the dual benefit of sugars and amino acids from the nectar of $B$. ovalifoliolata.

In B. ovalifoliolata, the flowers are weakly protandrous, produce considerable per cent of sterile pollen and present the capitate, wet papillate tri-lobed stigma above the stamens as in case of its allied species B. serrata (Sunnichan et al., 2005). The stigma receptivity ceases around noon time of the next day. These characteristics suggest that the tree species is adapted for crosspollination which is further substantiated by the lack of fruit set in manual self-pollination treatments. The reason for the failure of fruit set in these treatments appears to be the inhibition of self pollen tubes soon after their entry into the stigma. Therefore, the study suggests that $B$. ovalifoliolata is highly self-incompatible and obligate outcrosser like B. serrata (Sunnichan et al., 2005). According to Cruden (1977), the pollen production rate at flower level is not commensurate with out-crossing breeding system but it seems to be appropriate if the fruit set rate in manual cross-pollination is considered. Fruit set in open-pollination among individual trees is less than $10 \%$ but it is most likely to increase in the absence of bud/flower predation by weevil and squirrel. The extent of increase in fruit set in manual cross-pollination also has not exceeded 34\% and this suggests that there are inherent constraints to fruit set in addition to limitation of cross-pollination. The distribution of fruits on the inflorescence is sparse and hence, space is not a constraint for increased fruit set. As all fruits produced three seeds, there seems to be a space constraint in the ovary for seed set from all six ovules of the flower. The uniform number of seeds in each fruit seems to be an evolved and adaptive trait to compensate the lower fruit set in open-pollinations. It also suggests that cross-pollen availability is not a constraint in fruited flowers. In self-pollinated flowers, the deposited self pollen and the pollen tubes formed may prevent or block if the cross-pollen is subsequently deposited by insects/sunbirds. Further, the trees being leafless during the entire flowering and fruiting period have to utilize the available limited resources for fruit and seed loading. In consequence, the trees may even selectively disallow genetically inferior cross-pollinations to proceed further to set fruit in order to save available resources for pumping into the genetically superior fruits and seeds. The floor of the forest being rocky, dry and litter free during flowering and fruiting season deprives this tree species of nutrient resources. Therefore, B. ovalifoliolata with poor-nutrient environment is capable of performing reproductive events and produce some per cent of fruit set as a self-icompatible and obligate outcrosser. Similar reproductive events and constraints have been reported in B. serrata (Sunnichan et al., 2005). A recent experimental study with B. papyrifera by Toon et al. (2006) shows that intensive tapping for gum causes the trees to divert too much carbohydrate into resin at the expense of reproductive organs, such as flowers, fruit and seeds. In consequence, the trees produce fewer smaller fruits with seeds of lower weight and reduced vitality than non-tapped trees. Such a situation in B. ovalifoliolata can not be ruled out since it is an important source of gum resin for local tribes and hence there is a great threat to this globally endangered and endemic species.

Fruits mature in a short period and dehisce along the septa to disperse seeds for which dry conditions are essential. Their dispersal takes place in the month of May when temperature is at its maximum and which provides ideal conditions for seed dispersal by wind. The seed characteristics such as small size, light weight, papery and winged nature are adapted for anemochory. As the study site is windy, anemochory is very effective, dispersing seeds up to $400 \mathrm{~m}$ away from the parental site. Therefore, in B. ovalifoliolata, dry season seems to be the pre-requisite for flowering, fruiting and seed dispersal. Leaf flushing occurs immediately after seed dispersal and the water stress is released by rainfall in June and thereafter. During this period, with foliage, the tree has to produce and store the required energy for the recurrence of sexual reproduction in the next dry season. The dispersed seeds germinate readily following rainfall but their continued growth and development is related to soil water and nutritional status. Since the natural area of $B$. ovalifoliolata is rocky with little litter and soil moisture, the success rate of seedlings each year is very much limited and hence this could be one of the factors that give it the 'endemic and endangered' status. 


\section{Acknowledgement}

The first author is thankful to the University Grants Commission for financial assistance through a major research project. The second and third authors are project staff in the project and thank the UGC for fellowship for doing this research work.

\section{References}

Arabia, F. 2005. Taxonomy. Universita di Pisa, SignumScuola Normale Superiore di Pisa, http://arabiantica.humnet.unipi.it.

Baker, H.G., Baker, I. 1990. The predictive value of nectar chemistry to the recognition of pollinator types. Israel Journal of Botany, 39: 157-166.

Baker, H.G., Baker, I. 1986. The occurrence and significance of amino acids in floral nectar. Plant Systematics and Evolution, 151: 175-186.

Baker, H.G., Baker, I. 1983. A brief historical review of the chemistry of floral nectar. In: The Biology of Nectaries, B. Bentley and T. Elias (eds.), pp. 127-152, Columbia University Press, New York, USA.

Baker, H.G., Baker, I. 1982. Chemical constituents of nectar in relation to pollination mechanisms and phylogeny. In: Biochemical Aspects of Evolutionary Biology, M.H. Nitecki (ed.), pp. 131-171, The University of Chicago Press, Chicago, USA. Bhattacharya, K., Majumdar, M.R., Bhattacharya, S.G. 2006. A Textbook of Palynology (Basic and Applied), 352 pp., New Central Book Agency, Pvt. Ltd., Kolkata., India.

Chetty, K.M., Rao, K.N., Sudhakar, A. 2002. Angiosperm diversity on Seshachalam ranges of Eastern Ghats in Chittoor district of Andhra Pradesh, India. In: National Seminar on Conservation of Eastern Ghats, pp. 64-68, 24-26th March 2002 at Tirupati, EPTRI, Hyderabad, India.

Cruden, R.W., Hermann, H.M., Peterson, S. 1983. Patterns of nectar production and plant-pollinator co-evolution. In: The Biology of Nectaries, B. Bentley and T. Elias (eds.), pp. 80-125, Columbia University Press, New York, USA.

Cruden, R.W. 1977. Pollen-ovule ratios: a conservative indicator of breeding systems in flowering plants. Evolution, 31: 32-46.

Dafni, A., Kevan, P.G., Husband, B.C. 2005. Practical Pollination Biology, 590 pp., Enviroquest Ltd., Cambridge, Canada.

DeGroot, A.P. 1953. Protein and amino acid requirements of the honey bee (Apis mellifera L.). Physiologia Comparata et Oecologia, 3: 197-285.

Faegri, K., van der Pijl, L. 1979. The Principles of Pollination Ecology, 244 pp., Pergamon Press, Oxford, New York, USA.

Henry, K.H. 2006. Ecological and economic aspects of certain endemic flora of Eastern Ghats forests. ENVIS-SDNP Newsletter Special Issue 8-9.

Latheef, S.A., Prasad, B., Bavaji, M., Subramanyam, G. 2008. A database on endemic plants at Tirumala Hills in India. Bioinformation, 2: 260-262.

Opler, P.A. 1983. Nectar production in a tropical ecosystem. In: The Biology of Nectaries, B. Bentley and T. Elias (eds.), pp. 30-79, Columbia University Press, New York, USA.

Sandhya R.S., Pullaiah, T. 2002. A taxonomic survey of trees in Eastern Ghats. Proceeding of National Seminar on the Conservation of Eastern Ghats. pp. 5-15, India.

Solomon Raju, A.J.S., Rao, S.P. 2006. Nesting habits, floral resources and foraging ecology of large carpenter bees (Xylocopa latipes and Xylocopa pubescens) in India. Current Science, 90: 12101217.

Sudhakar, R.Ch., Murthy, M.S.R., Dutt, C.B.S. 2002. Vegetational diversity and endemism in Eastern Ghats, India. National Seminar on Conservation of Eastern Ghats, 24-26th March 2002 at Tirupati, pp. 109-134, EPTRI, Hyderabad, India.

Sunnichan, V.G., Mohan, R.H.Y., Shivanna, K.R. 2005. Reproductive biology of Boswellia serrata, the source of salai guggul, an important gum-resin. Botanical Journal of Linnean Society, 147: 73-82.

Toon, R., Woldeselassie, O., Marius, W., Frans, B. 2006. The effect of tapping for frankincense on sexual reproduction in Boswellia papyrifera. Journal of Applied Ecology, 43: 1188-1195. 